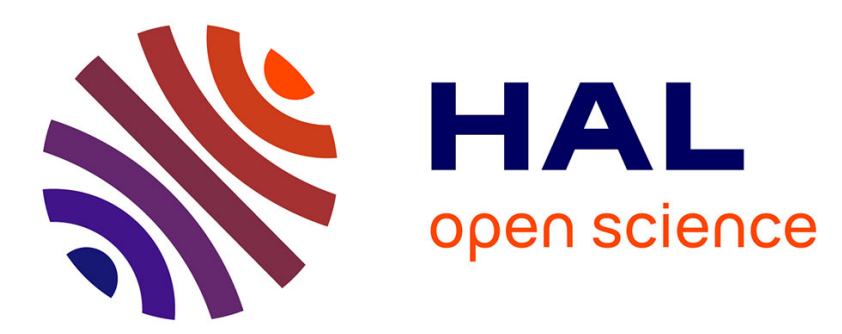

\title{
Large atomic disorder in nanostructured LaNi alloys: A La L-edge extended X-ray absorption fine structure study
}

B. Joseph, A. Iadecola, B. Schiavo, N.L. Saini

\section{- To cite this version:}

B. Joseph, A. Iadecola, B. Schiavo, N.L. Saini. Large atomic disorder in nanostructured LaNi alloys: A La L-edge extended X-ray absorption fine structure study. Journal of Physics and Chemistry of Solids, 2010, 71 (8), pp.1069. 10.1016/j.jpcs.2010.03.008 . hal-00661910

\section{HAL Id: hal-00661910 https://hal.science/hal-00661910}

Submitted on 21 Jan 2012

HAL is a multi-disciplinary open access archive for the deposit and dissemination of scientific research documents, whether they are published or not. The documents may come from teaching and research institutions in France or abroad, or from public or private research centers.
L'archive ouverte pluridisciplinaire HAL, est destinée au dépôt et à la diffusion de documents scientifiques de niveau recherche, publiés ou non, émanant des établissements d'enseignement et de recherche français ou étrangers, des laboratoires publics ou privés. 


\section{Author's Accepted Manuscript}

Large atomic disorder in nanostructured $\mathrm{LaNi}_{5}$ alloys: A La $\mathrm{L}_{3}$-edge extended $\mathrm{X}$-ray absorption fine structure study

B. Joseph, A. Iadecola, B. Schiavo, N.L. Saini

PII: $\quad$ S0022-3697(10)00054-5

DOI: $\quad$ doi:10.1016/j.jpcs.2010.03.008

Reference: $\quad$ PCS 6117

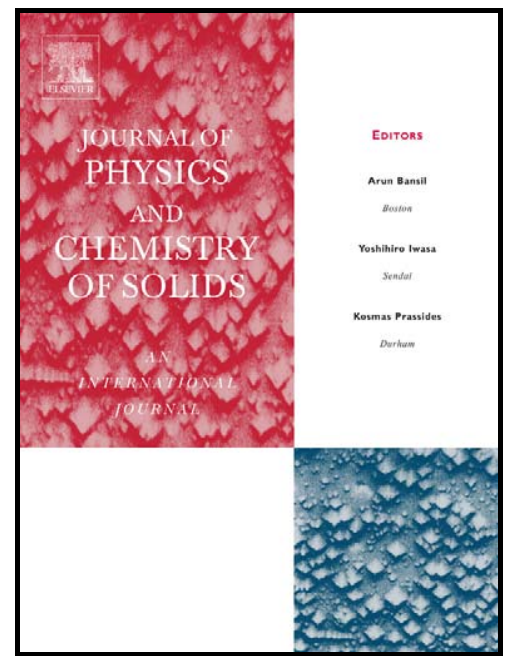

www.elsevier.com/locate/jpcs

To appear in: $\quad$ Journal of Physics and Chemistry of Solids

Cite this article as: B. Joseph, A. Iadecola, B. Schiavo and N.L. Saini, Large atomic disorder in nanostructured $\mathrm{LaNi}_{5}$ alloys: $\mathrm{A} \mathrm{La}_{3}$-edge extended $\mathrm{X}$-ray absorption fine structure study, Journal of Physics and Chemistry of Solids, doi:10.1016/j.jpcs.2010.03.008

This is a PDF file of an unedited manuscript that has been accepted for publication. As a service to our customers we are providing this early version of the manuscript. The manuscript will undergo copyediting, typesetting, and review of the resulting galley proof before it is published in its final citable form. Please note that during the production process errors may be discovered which could affect the content, and all legal disclaimers that apply to the journal pertain. 


\title{
Large Atomic Disorder in Nanostructured LaNi $i_{5}$ Alloys: A La L $\mathrm{L}_{3}$-edge Extended X-ray Absorption Fine Structure Study
}

\author{
B. Joseph ${ }^{1}$, A. Iadecola ${ }^{1}$, B. Schiavo ${ }^{2,3}$, N.L. Saini ${ }^{1}$ \\ ${ }^{1}$ Dipartimento di Fisica, Università di Roma "La Sapienza", P. le Aldo Moro 2, 00185 \\ Roma, Italy \\ ${ }^{2}$ Istituto Tecnologie Avanzate, Base di ASI Luigi Broglio, Strada Statale 113, Trapani, \\ 9100, Italy \\ ${ }^{3}$ Dipartimento di Fisica e Tecnologie Relative, Università di Palermo, Viale delle \\ Sicenze, Palermo, 90100, Italy
}

\begin{abstract}
Local structure of the nanostructured $\mathrm{LaNi}_{5}$ alloys, prepared by ball-

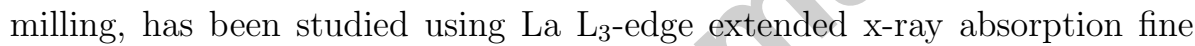
structure spectroscopy. The near-neighbour distances tend to decrease with the ball-milling, and the mean square relative displacements (MSRD) show substantial increase suggesting an increased atomic disorder. High temperature annealing helps in partial recovery of atomic order in the ball-milled samples for milling times upto $20 \mathrm{~h}$, however, the long-time ball-milled samples seems to gain only a local random order. The results suggest that reduced unit-cell volume together with large atomic-disorder might be causing a higher energy-barrier for the hydride-phase formation in the long time ball-milled $\mathrm{LaNi}_{5}$ powders.
\end{abstract}

Key words: $\mathrm{LaNi}_{5}$ alloys, Nanostructuring, Local structure, Atomic disorder

\section{Introduction}

With the growing enviornmental concerns of greenhouse gas emissions from the burning of fossil fuels, it is becoming increasingly important to switch to cleaner alternative fuels such as hydrogen [1]. One of the main 
concerns of the so called "hydrogen economy" is the suitable materials for the solid state storage of hydrogen satisfying the criterias required for a commercially viable system, especially for the transport sector [2]. The $\mathrm{LaNi}_{5}$ alloy qualifies all requirements to be an ideal $\mathrm{H}_{2}$-storage material for the vehicular applications albeit with lower hydrogen weight percentage. Indeed there are large research efforts underway to develop hydrogen storage materials with technical-specifications similar to that of $\mathrm{LaNi}_{5}$, but for a larger $\mathrm{H}_{2}$-absorption capacity. Nanostructing, especialy using a technique which enable industrial production, like the ball-milling, is one of the commonly used approaches to improve the hydrogenation properties of materials [3, 4, 5]. However, nanomaterials of $\mathrm{LaNi}_{5}$ produced by ball-milling exhibit inferior hydrogen storage properties [6] unlike other potentially important hydrogen storage materials like $\mathrm{Mg}$, in which an enormous improvement in the hydrogenation properties occurs upon nanostructuring [5]. In order to develop suitable nanomaterials with superior hydrogen absorption-desorption properties, the upmost task is to understand the physical properties of potential hydrogen storage materials when converted to nanoparticles. In this paper, we have addressed the issues related with nanostructuring verus hydrogen storage and studied $\mathrm{LaNi}_{5}$ using extended x-ray absorption fine structure (EXAFS) spectroscopy.

EXAFS is a site selective method, providing information on the local atomic distribution around a selected absorbing atom through photoelectron scattering [7]. Recently, this technique has been extensively used for the local structure studies of several nanomaterial systems $[8,9,10,11,12,13,14,15]$. Here, we have exploited the $\mathrm{La}_{3}$-edge EXAFS spectroscopy to make a systematic study of the local structure around the La atom, by measuring a series of $\mathrm{LaNi}_{5}$ samples, where the particle size is varied through ballmilling. The results suggest that the near-neighbour distances for the longtime ball-milled $\mathrm{LaNi}_{5}$ powders are smaller than the bulk, consistent with an expected lattice-parameter reduction for the nanoparticles. The related mean square relative displacements (MSRDs) are seen to increase with the nanostructuring, indicating a substantial atomic disorder. More importantly, the long-time ball-milled powders are found to retain large disorder even after the high temperature annealing. In fact, the annealing seems to cause only a random local atomic order for the $100 \mathrm{~h}$ ball-milled $\mathrm{LaNi}_{5}$. Large atomic disorder together with decreased interatomic distances for the nanostructured $\mathrm{LaNi}_{5}$ may be causing a higher energy barrier for the hydride phase formation. 


\section{Experimental Details}

Hydrogen storage grade $\mathrm{LaNi}_{5}$ samples from Sigma-Aldrich were used for the present study. Ball-milling of these samples were carried out using a FRITSCH miller (Pulverisette 6), using a stainless steel vial and stainless steel balls, at 240 rotations per minutes with a ball to powder ratio around 10 . Milling was carried out in cycles of 20 min milling-time and 20 min pause-time to avoid the over heating of the sample during the milling process. Samples were prepared with milling times 2, 20 and $100 \mathrm{~h}$. All sample handlings were carried out inside an Ar filled glove box (Mbraun) to avoid possible contacts with air. To study the annealing effect, a part of the $100 \mathrm{~h}$ ball-milled sample was annealed at $730^{\circ} \mathrm{C}$ for $1 \mathrm{~h}$, while the $20 \mathrm{~h}$ ball-milled sample was annealed at $500^{\circ} \mathrm{C}$ for the same time. Annealings were performed under high vacuum $\left(\sim 10^{-6}\right.$ mbar $)$.

The x-ray absorption measurements were made at the XAFS beamline of the Elettra Synchrotron Radiation Facility, Trieste, where the synchrotron radiation emitted by a bending magnet source was monochromatized using a double crystal $\mathrm{Si}(111)$ monochromator. The La $\mathrm{L}_{3}$ - EXAFS measurements were made at $90 \mathrm{~K}$ in the transmission mode using three ionization chambers mounted in series for simultaneous measurements on the sample and a reference (on-line calibration). More than one absorption scans were recorded for each sample to ascertain the reproducibility and to obtain spectra with high signal-to-noise ratio. Prior to the EXAFS measurements, the samples were characterized for their hydrogen absorption properties by measuring the pressure composition isotherms [6] using an automated PCT apparatus (HyEnergy). Standard procedure was used to extract the EXAFS oscillations from the absorption spectrum [7].

\section{Results and Discussion}

Figure 1 shows Fourier transforms (FTs) of the EXAFS oscillations extracted from the $\mathrm{La}_{3}$-edge $\mathrm{x}$-ray absorption spectra, measured at $90 \mathrm{~K}$ on the $\mathrm{LaNi}_{5}$ powders with variable ball-milling time. The FTs reveal the real space partial atomic distribution relative to the La atom. The FTs are performed between $\mathrm{k}_{\min }=2.5 \stackrel{\circ}{A}^{-1}$ and $\mathrm{k}_{\max }=9.8 \AA^{-1}$ using a Gaussian window. Due to the limited $k$-range it is impossible to provide precise distribution function, however, the experimental data range is sufficient to underline the major differences between the relative atomic distributions. 
Indeed a large damping of the signal is clearly seen in the FT amplitude for all the atomic pairs, revealing an overall decrease with increasing milling time. Incidentally, such a damping is known to occur in several systems when the bulk is nanostructured. For example, $\mathrm{Au}, \mathrm{Cu}, \mathrm{Ni}$ and Te nanoparticles $[8,9,10]$, nanocrystalline Fe prepared by ball-milling [12], substrate free $\mathrm{Pd}$ nanoparticles prepared by evaporation [15] and Ge [14] and Pt [13] nanoclusters synthesized by ion implantation etc. are found to show a systematic damping of the EXAFS oscillations compared to the bulk.

The EXAFS amplitude depends on several factors and could be given by the following general equation [7]:

$$
\begin{aligned}
\chi(k)= & \sum_{i} \frac{N_{i} S_{0}^{2}}{k R_{i}^{2}} f_{i}\left(k, R_{i}\right) \\
& \times e^{-\frac{2 R_{i}}{\lambda}} e^{-2 k^{2} \sigma^{2}} \\
& \times \sin \left[2 k R_{i}+\delta_{i}(k)\right]
\end{aligned}
$$

where $\mathrm{N}_{i}$ is the number of neighboring atoms at a distance $\mathrm{R}_{i}, \mathrm{~S}_{0}^{2}$ is the passive electrons reduction factor, $\mathrm{f}_{i}\left(\mathrm{k}, \mathrm{R}_{i}\right)$ is the backscattering amplitude, $\lambda$ is the photoelectron mean free path, and $\sigma_{i}^{2}$ is the correlated Debye-Waller (DW) factor, measuring the mean square relative displacements (MSRDs) of the photoabsorber-backscatterer pairs. Apart from these, the photoelectron energy origin $\mathrm{E}_{0}$ and the phase shifts $\delta_{i}$ should be known for modelling the EXAFS.

$\mathrm{LaNi}_{5}$ has $\mathrm{CaCu}_{5}$ type structure (see, e.g., Fig. 1, lower panel) with the $P 6 / \mathrm{mmm}$ symmetry $[16,17,19]$. Earlier XRD [19] and neutron [16] diffraction studies have shown the lattice parameters to be $a \approx b \approx 5.0143$ $\AA$ and $c \approx 3.97987 \AA$. Recent first principle studies [17, 18] could also reproduce these values with an accuracy of $1 \%$. In the crystal unit cell, La atoms occupy the 1 a site, whereas $\mathrm{Ni}$ atoms have two different positions, viz. $3 g$ and $2 c$. The unit cell of $\mathrm{LaNi}_{5}$ contains $1 \mathrm{La}$ atom, $3 \mathrm{Ni}$ atoms at $3 g$ site and $2 \mathrm{Ni}$ atoms at $2 c$ site. In this structural configuration there are six $\mathrm{Ni}$ atoms at a distance $\sim 2.89 \AA$ (2c site) from the La atom and $12 \mathrm{Ni}$ atoms at a distance $\sim 3.2 \AA$ ( $3 g$ 3g site). The main peak in the FT (Fig. 1, upper panel) is mainly due to the single scattering from the above two sets of $\mathrm{Ni}$ atoms. We have used conventional procedure to analyze the EXAFS signal [7] taking the above two sets of $\mathrm{Ni}$ atoms as the first two shells. Except the radial distances $\mathrm{R}_{i}$ and the corresponding DW factors $\sigma_{i}^{2}$, all other parameters were kept fixed in the least squares fit $\left(\mathrm{S}_{0}^{2}=1\right)$. The WINXAS package [20] was 
used for the model fit with calculated backscattering amplitudes and phase shift functions. The number of independent data points, $\mathrm{N}_{\text {ind }} \sim(2 \Delta \mathrm{k} \Delta \mathrm{R}) / \pi$ [7] was 9, enough for the four parameter fit used for the present analysis $\left[\Delta \mathrm{k}=7.3 \AA^{-1}\left(\mathrm{k}=2.5-9.8 \AA^{-1}\right)\right.$ and $\left.\Delta \mathrm{R}=2 \AA\right]$. The model fits are also included in Fig. 1 (solid lines).

The near neighbor distances and the corresponding MSRDs obtained from the above analysis are presented in Fig. 2. While the first La-Ni distance (corresponding to the six $\mathrm{Ni}$ atoms at the $2 c$ sites) is found to show neglibile change with milling time, the second La-Ni distance (corresponding to the twelve $\mathrm{Ni}$ atoms at the $3 g$ sites) is found to decrease with milling time. However, the MSRDs corresponding to both the distances are found to increase with increasing milling time indicating increased atomic disorder with milling. These results are consistent with the information derived from the Ni K-edge EXAFS data for the same system [11]. In fact, such an increase in atomic disorder, as evidenced by the enhanced Debye Waller factors in the EXAFS measurements, seems to be typical of several nanoparticle systems $[8,10,12,15,13,14]$.

Let us discuss the effect of annealing on the ball-milled $\mathrm{LaNi}_{5}$ samples. Figure 3 shows the FTs of the EXAFS data for the 20 and $100 \mathrm{~h}$ milledand-annealed samples, along with the data from the bulk sample. For the $20 \mathrm{~h}$ milled powders, annealing seems to restore the near neighbor distances to the bulk value. There is also a substantial improvement in the atomic order, as evidenced by the enhancement in the magnitude of the FTs after annealing, which closely follows the pattern of the bulk (Fig 3). On the other hand, for the $100 \mathrm{~h}$ milled sample, the high temperature annealing seems to be insufficient to restore the interatomic distances and the atomic order. In this case, a somewhat significant enhancement in the intensity of the peak corresponding to the first two set of near-neighbors (Fig. 3), may appear to indicate an enhanced atomic ordering. But, a careful analysis reveal that this enhancement in peak intensity is not symmetric for the two set of near-neighbors, unlike in the $20 \mathrm{~h}$ case. As discussed earlier, long time ball-milling results in substantial disordering in the system, and high temperature annealing of such a disordered system can possibly bring random ordering, causing a small fraction of the orginal Ni sites to be occupied by La. Such a random local ordering can cause enhancement in the FT intensity of the annealed sample due to the larger atomic scattering factor of the heavier element La compared to the lighter element Ni. Absence of the enhancement in FT magnitudes corresponding to the further shells (Fig. 3) also support 
the above conjucture.

As far as the hydrogen uptake capacity, it is found that the capacity decreases gradually with the increasing ball-milling time, however, the capacity could be regained by the high-temperature annealing, albeit with slow hydrogenation kinetics [6]. It should be recalled that after annealing, the equilibrium plateau pressure, where the continuous conversion of the $\alpha$ to $\beta$ phase occurs, is found to be highest for the $100 \mathrm{~h}$ ball-milled samples [6]. Results from the present $\mathrm{La} \mathrm{L}_{3}$-edge EXAFS together with the the Ni K edge EXAFS [11], clearly indicate that there is a decrease in the near-neighbour distances and an increase in the corresponding MSRD for the nanoparticles of $\mathrm{LaNi}_{5}$ produced by long-time ball-milling of the bulk. High temperature annealing is found to results in only some random local ordering in the system, thus incapable of restoring the global atomic order in nanostructured $\mathrm{LaNi}_{5}$. This increased atomic disorder in the nanostructured phase may be one of the main reasons behind the enhanced resistance to the hydrogenation reaction of the long time ball-milled $\mathrm{LaNi}_{5}$. In this scenario, the local structural studies of $\mathrm{Mg}$, which seems to show significant improvements in its hydrogenation properties upon long-time ball-milling is going to be very relevant for obtaining further insights for the developement of nanostructured hydrogen storage materials with superior hydrogenation properties.

In summary, La $\mathrm{L}_{3}$-edge EXAFS studies of the nanostructured $\mathrm{LaNi}_{5}$ alloys, reveals large atomic disorder as evidenced by the large values of the relative mean square displacements of bondlengths with increasing millingtime. High temperature annealing helps in partial recovery of atomic order in the ball-milled samples, however with a substantial random atomic order for the long-time ball-milled samples. Observed enhanced atomic disorder seems to have important contributions to the sluggish hydrogenation properties of the nanostructured $\mathrm{LaNi}_{5}$.

\section{Acknowledgements}

The XAFS measurements were carried out under the proposal number 20090071 at the XAFS beamline of the Elettra synchrotron facility, Trieste, Italy. The authors thank the beamlime staffs for the help and cooperation during the experimental runs. One of us (BJ) would like to acknowledge the MIUR (Italy) for a fellowship under the India-Italy bilateral programme. 


\section{References}

[1] S. Kahn Ribeiro et al., Transport and its infrastructure in Climate Change, Contribution of working group III to the Fourth Assement Report of Inter-governmental Panel on Climate Change, B. Metz, O. R. Davidson, P.R. Bosch, R. Dave, L.A. Meyers (eds), Cambridge Uni. Press. Cambridge UK \& NY USA, 2007.

[2] A. W. C. van den Berg, C. O. Aren, Chem. Commun. 668-681 (2008), DOI10.1039/b712576n; D. Chandra, J. Reilly, and R. Chellappa, JOM Journal of the Minerals, Metals and Materials Society 58, 26 (2006); L. Schlapbach and A. Zuttel, Nature 414, 353 (2001).

[3] A.M. Seayad, D.M. Antonelli, Adv. Mater. 16, 765-777, 2004; A. S. Arico, P. Bruce, B. Scrosati, J.-M. Tarascon, and W. van Schalkwijk, Nat. Mater. 4, 366 (2005); B. Vincent, R. Gregg, D. Mildred, and C. Gang, Int. J. Energy Res. 31, 637 (2007); See special issue, J. Vajo, F. Pinkerton, N. Stetson, Nanoscale phenomena in hydrogen storage, Nanotechnology 20, 200201 (2009)

[4] U. Shaym, M.G. Norton, J. Mater Sci. 43, 5395-5429 (2008); M. Fichtner, Adv. Eng. Mater. 7, 443 (2005)

[5] A. Zaluska, L. Zaluski, and J. O. Ström-Olsen, J. Alloys Compd. 288, 217 (1999); M. Dornheim, N. Eigen, G. Barkhordarian, T. Klassen, and R. Bormann, Adv. Eng. Mater. 8, 377 (2006); M. Dornheim, S. Doppiu, G. Barkhordarian, U. Boesenberg, T. Klassen, O. Gutfleisch, and R. Bormann, Scripta Materialia 56, 841 (2007); M.V. Lototsky, R.V. Denys, V.A. Yartys, Int. J. Energy Res. 33, 1114-1125 (2009)

[6] B. Joseph and B. Schiavo, J. Alloys Compd. 480, 912 (2009).

[7] X-ray Absorption: Principles, Applications, Techniques of EXAFS, SEXAFS, XANES Eds. R. Prinz, D. Koningsberger (Wiley, New York, 1988).

[8] A. Balerna, E. Bernieri, P. Picozzi, A. Reale, S. Santucci, E. Burattini, and S. Mobilio, Phys. Rev. B 31, 5058 (1985); T. Comaschi, A. Balerna, and S. Mobilio, Phys. Rev. B 77, 075432 (2008). 
[9] G. Apai, J. F. Hamilton, J. Stohr, A. Thompson, Phys. Rev. Lett. 43, 165 (1979);

[10] H. Ikemoto, T. Miyanaga, Phys. Rev. Lett. 99, 165503 (2007)

[11] B. Joseph, A. Iadecola, B. Schiavo, A. Cognigni, L. Olivi, G. D'Alì Staiti, N.L. Saini, J. Sol. State Chem. (submitted)

[12] A. Di Cicco, M. Berrettoni, S. Stizza, E. Bonetti, and G. Cocco, Phys. Rev. B 50, 12386 (1994).

[13] R. Giulian, L. L. Araujo, P. Kluth, D. J. Sprouster, C. S. Schnohr, G. J. Foran, and M. C. Ridgway, J. Phys.: Condens. Matter 155302 (2009).

[14] L. L. Araujo, R. Giulian, D. J. Sprouster, C. S. Schnohr, D. J. Llewellyn, P. Kluth, D. J. Cookson, G. J. Foran, and M. C. Ridgway, Phys. Rev. B 78, 094112 (2008).

[15] L. Chih-Ming, H. Tsu-Lien, H. Yen-Heng, W. Kung-Te, T. Mau-Tsu, L. Chih-Hao, C. T. Chen, and Y. Y. Chen, Phys. Rev. B 75, 125426 (2007).

[16] P. Thompson, J. J. Reilly, L. M. Corliss, J. M. Hastings, and R. Hempelmann, J. Phys. F: Met. Phys. 16, 675 (1986); A. Percheron-Gugan, C. Lartigue, J. C. Achard, P. Germi, and F. Tasset, J. Less Common Metals 74, 1 (1980).

[17] Y. Yu, H. Han, Y. Zhao, W. Xue and T. Gao, Solid State Commun. 148, 1 (2008); K. Tatsumi, I. Tanaka, H. Inui, K. Tanaka, M. Yamaguchi, and H. Adachi, Phys. Rev. B 64, 184105 (2001).

[18] K. Tatsumi, et al., J. Phys. Condes. Matter 15, 6549 (2003); C. Zhang et al., J. Alloys Compd 439, 25 (2007); A.F. Alam et al., Solid State Sci. 11,1098 (2009)

[19] Y. Nakamura, K. Oguro, I. Uehara, and E. Akiba, Int. J. Hydrogen Energy 25, 531 (2000).

[20] T. Ressler, J. of Synch. Rad. 5, 118 (1998). 

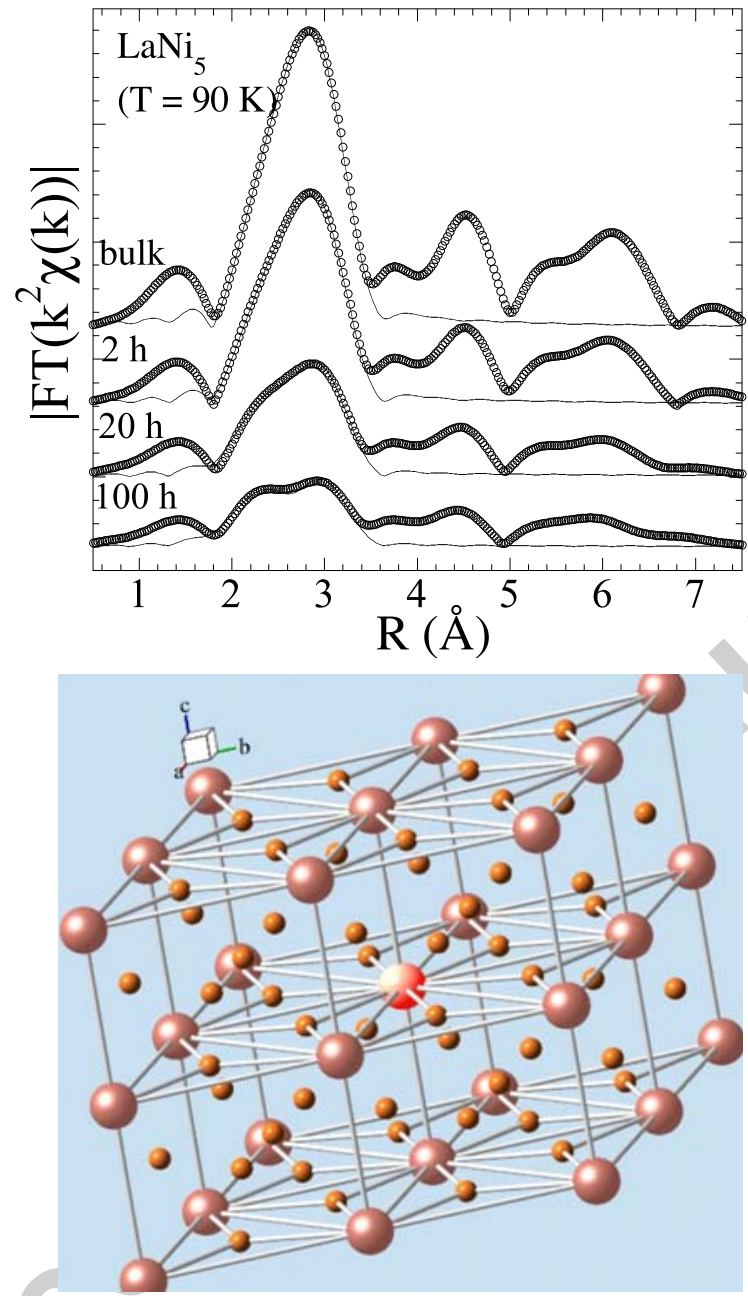

Figure 1: (color on-line) Fourier transforms (FTs) of the $\mathrm{La}_{3}$-edge EXAFS oscillations showing partial atomic distribution around the La (upper). FTs are performed between $\mathrm{k}_{\min }=2.5 \AA^{-1}$ and $\mathrm{k}_{\max }=9.8 \AA^{-1}$ using a Gaussian window. A model fit with two shells representing the two La-Ni near neighbours (solid line) is also included. Structural model for $\mathrm{LaNi}_{5}$ crystal system is also shown (lower). This model contains 8 unit-cells, where La atoms are represented by larger spheres. It is possible to notice the two set of near neighbour $\mathrm{Ni}$ atoms around the highlighted La atom (six and twelve around 2.89 and 3.2 $\AA$ respectively) used for the model fit shown in the upper panel. 


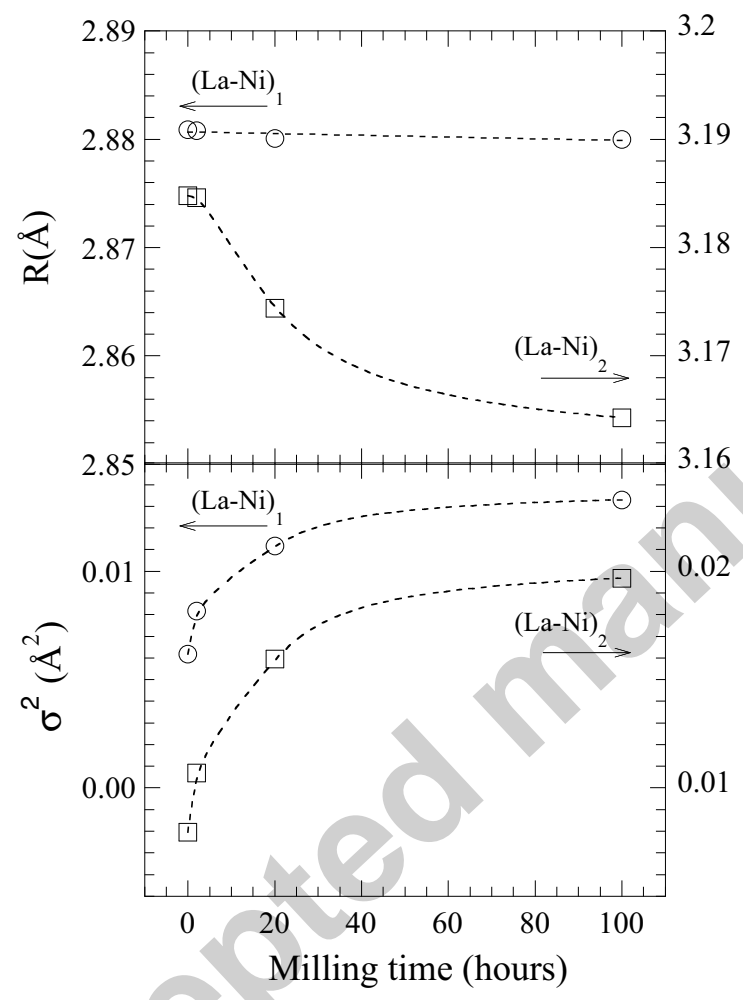

Figure 2: The near-neighbour La-Ni distances (upper) and the corresponding mean square relative displacements (lower) obtained from the 2 shell EXAFS fit as a function of the milling time. While the first distance remains constant (open circles), the second distance is found to decrease with milling time (open squares). However, MSRDs corresponding to both the distances are found to increase with increasing milling time indicating increased atomic disorder. Dotted lines are only a guide to eyes. 


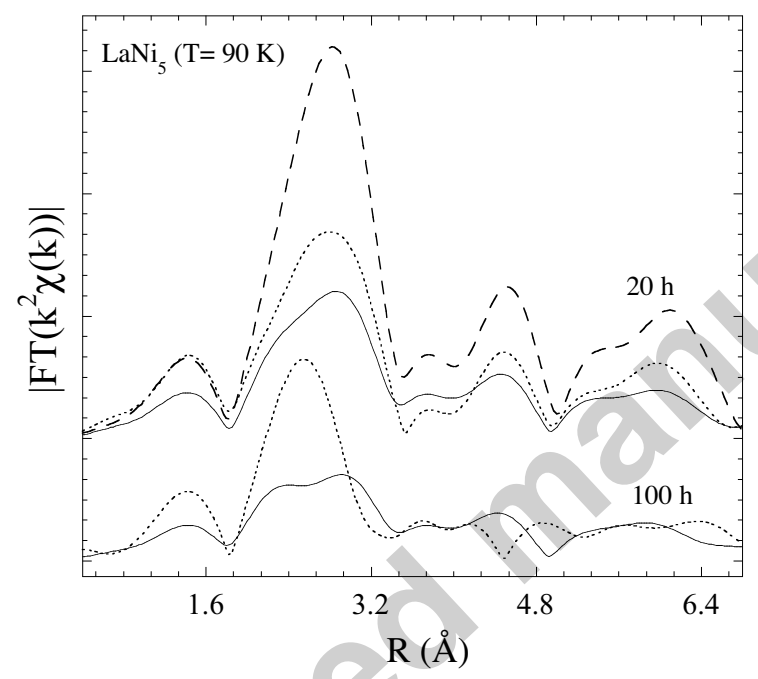

Figure 3: Fourier tranforms (FTs) of the La $\mathrm{L}_{3}$-edge EXAFS oscillations measured before (solid line) and after (dotted line) the high temperature annealing. The atomic order seems to substantially restored for the $20 \mathrm{~h}$ ball-milled sample after annealing, while the annealing of the $100 \mathrm{~h}$ ball-milled sample seems to retain large disorder even after annealing. The FT of the bulk sample is also shown for comparison (dashed line). 